Çukurova Üniversitesi Mühendislik Fakültesi Dergisi, 36(2), ss. 297-304, Haziran 2021

Cukurova University Journal of the Faculty of Engineering, 36(2), pp. 297-304, June 2021

\title{
Su Kanalı İçerisinde Isıtılmış Dairesel Bir Silindir Çevresinde Sıcaklık Ölçüm Sistemi Tasarımı
}

\author{
Doğan Burak SAYDAM${ }^{1}$, Ertaç HÜRDOĞAN*1, Coşkun ÖZALP1

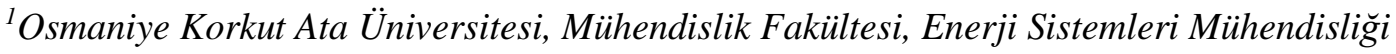 \\ Bölümü, Osmaniye
}

Geliş tarihi: 08.03.2021

Kabul tarihi: 30.06 .2021

$\ddot{\mathbf{O} z}$

Bu çalışmada, dairesel bir silindir etrafındaki ısı transferinin incelenebilmesi için tasarlanmış bir sıcaklık ölçüm sistemi ele alınmıştır. Çalışmada, alüminyum bir silindir içerisine yerleştirilen elektrikli rezistans vasıtasıyla silindir yüzeyinde sabit sıcaklık elde etmek için bir sıcaklık ölçüm sistemi tasarlanmış ve ilk ölçümlerin değerlendirilebilmesi amacıyla farklı Reynolds (Re) sayıları için silindir etrafındaki sıcaklık değişimleri incelenmiştir. Açık su kanalı içerisinde yapılan deneylerdeki sıcaklık ölçümlerinin anlık izlenebilmesi, kontrolü ve kayıt altına alınabilmesi için bir Merkezi Kontrol ve Veri Toplama Sistemi (SCADA) sistemi kurulmuş, ölçümlerin doğruluğu için gerekli kalibrasyonlar yapılmış ve ölçüm sistem bileşenlerinin belirsizlikleri hesaplanmıştır. Yapılan deneylerden elde edilen veriler sonucunda, tasarlanan sıcaklık ölçüm sisteminin sorunsuz bir şekilde çalıştığı görülmüştür. Farklı Re sayılarında yapılan deneylerden, sıcaklıkların akışa bağlı olarak silindir çevresi boyunca değişim gösterdiği ayrıca Re sayısının artması ile silindir çevresindeki sıcaklığın düştüğü görülmüştür.

Anahtar Kelimeler: Isıtılmış silindir, Açık su kanalı, Sıcaklık ölçümü, Isı transferi

\section{Design of a System for Temperature Measurement Around a Heated Circular Cylinder in a Water Channel}

\begin{abstract}
In this study, a temperature measurement system designed to investigate the heat transfer around a circular cylinder was considered. In the study, a temperature measurement system was designed to obtain a constant temperature on the cylinder surface by means of an electrical resistance placed in an aluminum cylinder, and the change of temperature around the cylinder was investigated for different Reynolds (Re) numbers within the scope of the evaluation of the first measurements. A Supervisory Control and Data Acquisition (SCADA) system was established in order to instantly monitor, control and record the temperature measurements in the experiments carried out in the open water channel, the necessary calibrations were made for the accuracy of the measurements and the uncertainties of the measurement system components were calculated. As a result of the data obtained from the experiments, it has been seen that the designed temperature measurement system works without any problems. From the experiments conducted with different Re numbers, it was observed that the temperatures varied along the circumference of the cylinder depending on the flow and the temperature around the cylinder decreases with the increase of Re number.
\end{abstract}

Keywords: Heated cylinder, Open water channel, Temperature measurement, Heat transfer

*Sorumlu yazar (Corresponding author): Ertaç HÜRDOĞAN, ehurdogan@osmaniye.edu.tr 


\section{GíRiș}

Isı geçişinin belirlenmesi, yanma odaları, endüstriyel kazanlar, döküm uygulamaları, binaların termal yönetimi, havacılık mühendisliği gibi farklı teknoloji ve mühendislik uygulamalarında büyük öneme sahiptir. Bununla birlikte, 1sı geçişi veya 1sı transfer katsayısının belirlendiği bir yüzeye erişim her zaman mümkün olamamaktadır [1]. Giydirilmiş yüzeylerde yüzey sıcaklığı, 1Sı transferi analizlerinde ölçülecek başlıca parametrelerden biridir. Fakat dıştan zorlanmış konveksiyon koşullarına maruz bırakılan bir cismin yüzey sıcaklığının ölçülmesi oldukça zor bir uygulamadır ve 1sıtılmış yüzeylerde uygun yüzey sıcaklığı ölçüm tekniklerine ilişkin bilgiler çok sınırlıdır. Yüzey sıcaklık ölçümünde kullanılacak olan tekniğin akış ve yüzey koşullarını olumsuz etkilememesi de ölçüm yapılırken dikkat edilmesi gereken en önemli unsurlardan bir tanesidir [2,3]. Değişken şartlara sahip ortamların veya yüzeylerin sıcaklık ölçümünde, basit yapısı, düşük maliyeti ve sağlamlığı nedeniyle isıl eleman çiftleri (termokupllar) yaygın olarak kullanılmaktadir [4].

Literatürde, değişken şartlara sahip ortamlarda yer alan cisimlerdeki yüzey sıcaklıklarının ölçülmesi ile ilgili farklı çalışmalar yer almaktadır [5-10]. Tsutsui ve Igarashi [5], bir rüzgâr tünelinde silindir etrafındaki ısı geçişini incelemek için bir akrilik reçineden imal edilen borunun yüzeyini $0,02 \mathrm{~mm}$ kalınlığında paslanmaz çelik sac ile kaplamışlardır. Paslanmaz çelik sacların alt tarafına her bir ölçüm noktasının arası $10^{\circ}$ aralıklarla konumlandırılacak şekilde $0,1 \mathrm{~mm}$ çapında bakır-konstantan (C-C) 1sıl çiftler yerleştirerek sicaklık ölçümlerini gerçekleştirmişler ve yüksek doğrulukta ölçüm sonuçları elde etmişlerdir. Gau ve arkadaşları [6], rüzgâr tünelinde 1sıtılmış yatay bir silindirin akış ve 1S1 geçişini incelemişlerdir. Çalışmada silindirin çevresini $0,015 \mathrm{~mm}$ kalınlığındaki ince paslanmaz çelik folyo ile kaplamışlar ve daha sonra elektrik akımını folyodan geçirerek silindir yüzeyi istenen seviyede homojen olarak 1sıtmışlardır. Euler ve arkadaşları [7], katmanlı girdap gövdeli bir brülörün (Cambridge/Sandia Stratified Swirl Burner) yüzey
Sıcaklığı ölçümlerinin incelemesini yapmışlardır. Yazarlar, yüzey sıcaklık ölçümlerini lazer kaynaklı fosforlama (phosphorescence) tekniği ile gerçekleştirmişlerdir. S1caklıklar, fosforun bozulma süresinin ölçülmesiyle elde edilmiştir. Çalışma sonucunda, sıcaklığın farklı çalışma koşulları için 550-900 K aralığında değiştiğini gözlemlenmiştir. Yan ve arkadaşları [8], bir spektrometre ve yüksek hızlı bir kameranın eşzamanlı kullanımıyla nesnelerin sıcaklık ölçümü üzerine bir çalışma yapmışlardır. Çalışmada sıcaklıklar spektrometre ve yüksek hızlı kamera kullanılarak dört farklı alev koşulunda ölçülmüş ve isıl eleman çiftlerinin sıcaklık ölçümleri ile karşılaştırılmıştır. Isıl eleman çiftleri vasıtasıyla alınan veriler, bir veri toplama kartına bağlanarak LabVIEW programı yardımıyla işlenmiştir. Çalışma sonucunda tasarlanan sistemin, yanma sırasında değişken sıcaklık ve emisyon değerlerine sahip katı yakıt parçacıkları gibi nesnelerin sicaklık ölçümleri için kullanılabileceğinin uygun olabileceği vurgulanmıştır.

Literatürde yer alan yüzeyden sıcaklık ölçümü çalışmalarında farklı yöntemler kullanılmakla birlikte özellikle akış ve 1sı transferi özelliklerinin birlikte incelendiği silindirik cisimlerin sıcaklık ölçümü çoğunlukla rüzgâr tünelinin kullanılması ve cisim üzerine farklı metal aksesuarların giydirilmesi sonucunda yapılmıştır. Bu çalışmada ise farklı yüzey geometrisine sahip dönen ve dönmeyen silindirlerin akış ve 1 ș geçişine etkilerinin deneysel olarak incelenmesi için bir su kanalı içerisinde bulunan 1sıtılmış dairesel bir silindir etrafında sıcaklık ölçüm sisteminin tasarımı yapılmış ve ilk deneysel sonuçlar analiz edilmiştir. Çalışma bu yönüyle özellikle su kanalı içerisinde yüzeyden sıcaklık ölçümü yapılacak uygulamalara referans olmayı hedeflemektedir.

\section{MATERYAL VE METOT}

\subsection{Materyal}

Çalışmada kapsamında tasarımı yapılan sistemde sıcaklık ölçümleri için $\mathrm{K}$ tipi isıl eleman çiftleri kullanılmıştır. Isıl eleman çiftleri iki farklı alaşımın ucunun birleştirilmesi ile oluşturan basit bir sıcaklık 
ölçüm elemanıdır. Kaynak noktası sıcak nokta, diğer açık iki uç soğuk nokta (veya referans noktası) olarak anılır. Isıl eleman çiftinin ölçüm prensibi sıcak nokta ile soğuk nokta arasındaki sıcaklık farkından doğar. Bu sıcaklık farkına orantılı, soğuk nokta uçlarında $\mathrm{mV}$ mertebesinde gerilim üretilir. Isıl eleman çiftlerinin daha doğru ve hassas ölçüm yapabilmesi için tel uçlarının birbirleri ile birleştirilmesinde kaynak yöntemi kullanılmaktadır [11].

Sıcaklık ölçümünde kullanılacak ısıl eleman çiftleri ile ilgili çalışmaların (uçların birleştirilmesi, izolasyon, vb.) tamamlanmasından sonra 1sıtılmış yüzeye sahip silindirlerin imalat aşamasına geçilmiştir. Öncelikle alüminyum malzemeden yapılmış silindir bloğunun içi, fişek tipi 1sıtıcı rezistansı (Şekil 1) yerleştirebilmek için boşaltılmıştır. Daha sonra silindir etrafındaki isı geçişinin incelenebilmesi amacıyla silindir çevresi boyunca silindir merkezi referans alınarak eşit açılarla $\left(45^{\circ}\right)$ konumlanmış 8 noktada dış yüzey sıcaklıkları ölçüm noktaları belirlenmiş ve bu noktalara isıl eleman çiftlerini yerleştirebilmek için silindir derin delme yöntemi ile delinmiştir. Şekil 2'de deney silindirinin üst ve yan görünüşünün yer aldığı teknik çizimler yer almaktadır. Şekil 3a'da deneylerde kullanılmak üzere tasarlanarak imal edilen ve içerisinde isitıcı bulunan ve 1sıl eleman çiftleri için oluşturulan deliklerin bulunduğu deney silindirinin, Şekil 3b'de ise 1sıl eleman çiftlerinin silindir içerisine yerleştirildiği halinin görselleri yer almaktadır. Deney silindirinde, çevresi boyunca eşit açılara ayrılarak silindir merkezini referans alacak şekilde oluşturulan sekiz noktadan, 1sıl eleman çiftleri ile ölçüm alınmaktadır. Şekil 4'de silindirin yüzeyinden sıcaklık ölçümü yapılabilmesi için oluşturulan ölçüm noktalarının görseli yer almaktadır. Silindir yüzeyinde ölçüm noktalarına açılan deliklerin içerisine sıkı geçme yöntemi ile yerleştirilmek üzere torna işlemi ile eşdeğer kapaklar imal edilmiş ve isıl eleman çiftlerinin birleştirilmiş uçları kapaklara tutturulmuştur. Kapakların bulunduğu noktalar ve silindir alt ve üst yüzeyleri, su izolasyonunu sağlamak için sıvı conta ile kaplanmıştır. Bu sayede kanal içerinden ölçüm noktalarına ve deliklerin içerisine su girişi engellenmiştir.

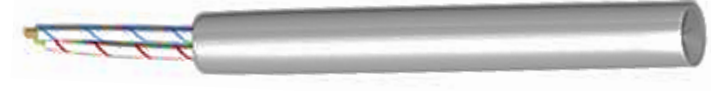

Şekil 1. Fişek tipi 1sıtıcı rezistansın gerçek resmi

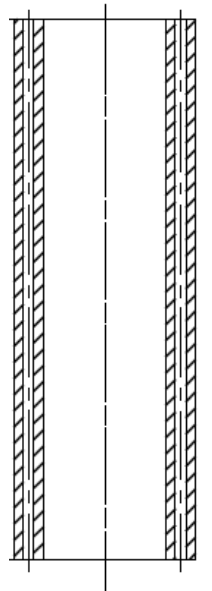

(a)

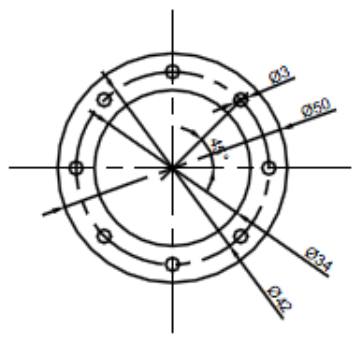

(b)
Şekil 2. Isıtılan silindirin yan (a) ve üst (b) görünüşüne ait teknik çizim

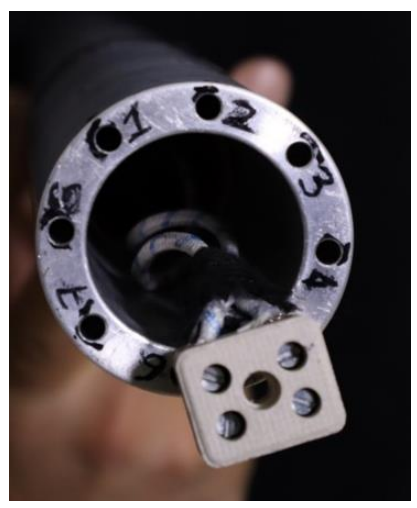

(a)

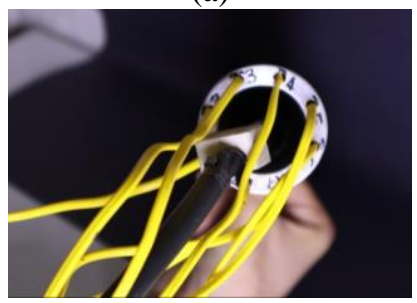

(b)

Şekil 3. Deney silindirinin (a), ve 1sıl eleman çiftlerinin yerleştirilmiş halinin (b) resmi 


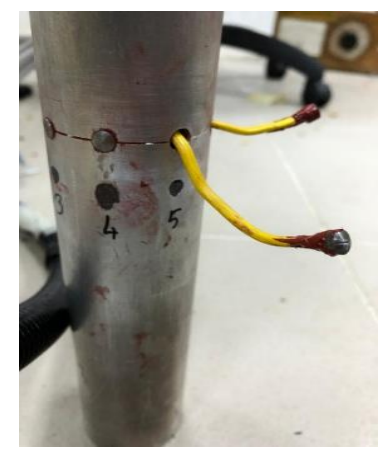

Şekil 4. Silindirin yüzeyinde oluşturulan ölçüm noktalarının resmi

\subsection{Yöntem}

Isıtılmış yüzeye sahip silindirlerin imalat aşamasının tamamlanmasından sonra hareket sistemi ve sıcaklık ölçüm sistemleri kurulmuş ve bu sistemlerin kontrolünde kullanılacak otomasyon panosu devreye alınmıştır. Şekil 5'de tüm kontrollerin yapıldı̆̆ 1 SCADA sistemine ait görsel yer almaktadır. Şekilde, deneylerin yapıldığı kapalı devre açık su kanalının, hareket sisteminin, sıcaklık ölçümlerinin anlık olarak izlendiği ve kaydedildiği sıcaklık ölçüm sisteminin ve silindir yüzey sıcaklıklarının değiştirilmesinde kullanılan varyak sistemi görülebilmektedir. Sistemde kapalı devre açık su kanalında akışın hızını ve kanallar arasında su sirkülasyonunun gerçekleştirilmesini sağlayan iki adet eksenel santrifüj pompa yer almaktadır. SCADA sisteminde ayrica silindir etrafında sıcaklıkların ölçüldüğü ve ölçümlerin anlık olarak izlendiği sıcaklık ölçüm sisteminin ve bir varyak ile silindir içerisinde bulunan rezistansin kontrol edildiği varyak kontrol sistemi de yer almaktadır (Şekil 6).

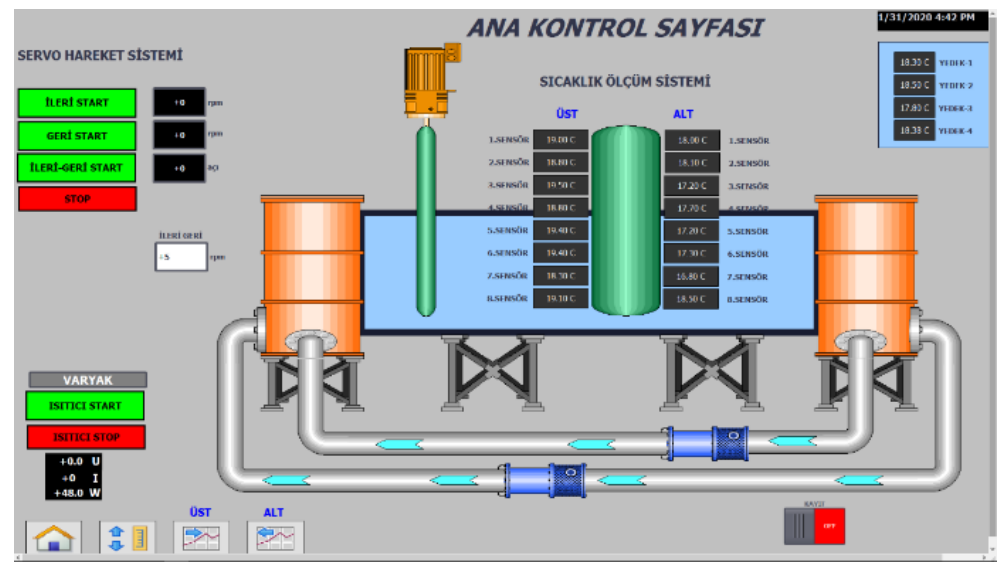

Şekil 5. SCADA sisteminin anlık ekran görüntüsü

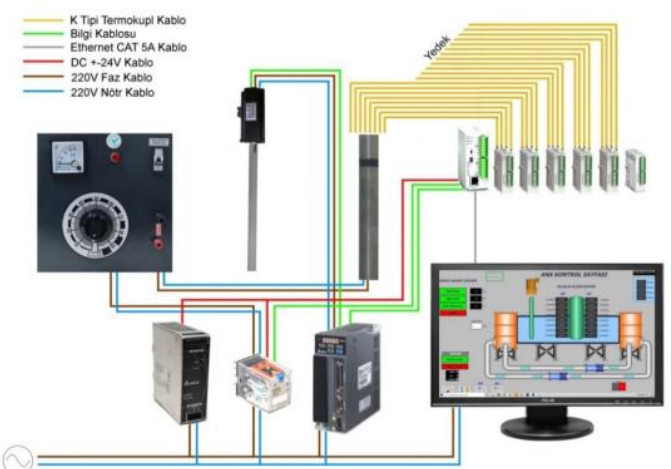

Şekil 6. S1caklık ölçüm ve kontrol sisteminin şematik gösterimi 
Isıtılacak silindirlerin imalatı ve sıcaklık ölçüm sisteminin kurulmasından sonra sicaklık ölçümlerinde kullanılacak 1sıl eleman çiftlerinin kalibrasyonu çalışmalarına geçilmiştir. Kalibrasyon çalışmalarında, referans sıcaklık tespiti için TÜRKAK standartlarına göre yapılmış güncel kalibrasyon sertifikasına sahip TESTO marka 435 model numaralı sıcaklık ölçüm cihazı kullanılmıștır. Silindir etrafındaki sıcaklık değişiminin ölçümünde kullanılacak ısıl eleman çiftlerinin kalibrasyonu farklı sıcaklıklar için yapılmıştır. Şekil 7'de kalibrasyon yapabilmek için oluşturulan kalibrasyon düzeneği (su banyosu) ve çalışmalara ait görseller yer almaktadır. Oluşturulan düzeneğin etrafı 1sı kayıplarını en alt seviyeye indirgeyebilmek için $5 \mathrm{~cm}$ cam yünü ile kaplanmıştır.

Düzeneğin içerisine farklı sıcaklıklarda (buzlu su, sıcak su, soğuk/sıcak su karışımı) akışkan gönderilerek kalibrasyon çalışmaları için gerekli farklı sıcaklık değerleri elde edilmiştir.
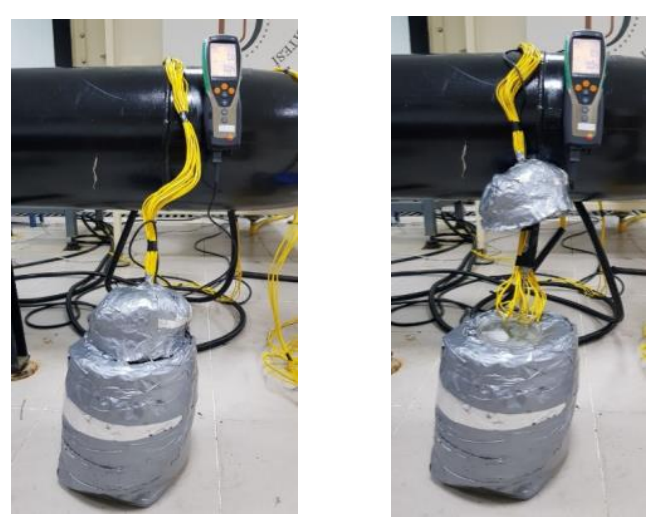

Şekil 7. Kalibrasyonların gerçekleştirildiği deney düzeneği

\section{BULGULAR}

Sistemde kullanılacak 1sıl eleman çiftlerinin (8 adet) kalibrasyonu için 6 farklı sıcaklıkta $\left(\cong 1^{\circ} \mathrm{C}\right.$, $\left.4^{\circ} \mathrm{C}, \quad 20^{\circ} \mathrm{C}, \quad 33^{\circ} \mathrm{C}, \quad 45^{\circ} \mathrm{C}, \quad 63^{\circ} \mathrm{C}\right)$ testler gerçekleștirmiștir. Her bir test sicaklığında (her test 15 dakika süreyle yapılmıştır), 1sıl eleman çiftleriyle ölçülen sicaklık $\left(\mathrm{T}_{\mathrm{IEÇ}}\right)$, TESTO referans cihazıyla ölçülen sicaklıkla ( $\left.\mathrm{T}_{\text {TESTO }}\right)$ karşılaştırılarak her bir 1 sıl eleman çifti için kalibrasyon eğrileri oluşturulmuştur. Şekil 8'de örnek olarak 1 (Şekil 8a) ve 5 (Şekil 8b) nolu 1sil eleman çiftleri (sensor) için elde edilmiş eğrilere ait grafikler yer almaktadır. Şekiller incelendiğinde oluşturulan formüllerde yakınsamanın çok iyi olduğu $\left(\mathrm{R}^{2}=1\right)$ görülmektedir. Benzer eğriler diğer 1sıl eleman çiftleri için de elde edilmiştir. Kullanılacak her bir ısıl eleman çiftinin kalibrasyon eğrilerinin elde edilmesiyle ölçümlerin doğruluğu sağlanmıştır. Şekil 9 ve $10^{\prime}$ da sırasıyla düşük $\left(\cong 1^{\circ} \mathrm{C}\right)$ ve yüksek $\left(\cong 63^{\circ} \mathrm{C}\right)$ sicaklıkta yapılan testlerde, isıl eleman çiftlerinin kalibrasyon öncesi ve sonrasındaki sıcaklıkların değişimi verilmiştir. Şekillerden, kalibrasyon eğrileri ile düzeltilmeden önce gerçek sıcaklık değerleri (Testo) ve isıl eleman çiftleri (1-8. sensör) ile ölçülen sıcaklıklar arasındaki farklılıkların, kalibrasyon çalışması sonunda elde edilen eğriler kullanılmasıyla ortadan kalktığı (düzeltilen 1sıl eleman çifti sıcaklık değerleri, gerçek değere yaklaşmıştır) dolayısıyla elde edilen eğrilerin kullanılabilir olduğu görülmektedir.

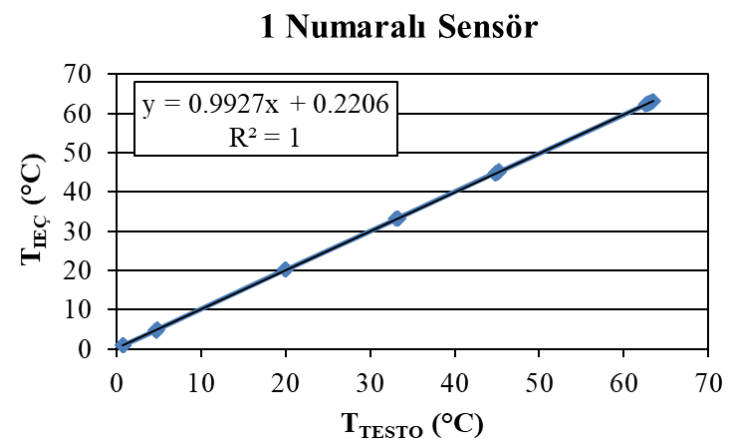

(a)

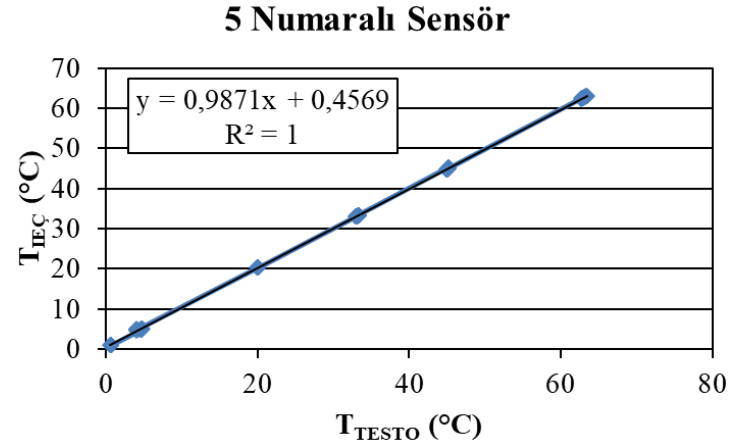

(b)

Şekil 8. 1(a) ve 5(b) nolu isıl eleman çiftlerine ait kalibrasyon eğrilerinin yer aldığı grafikler 


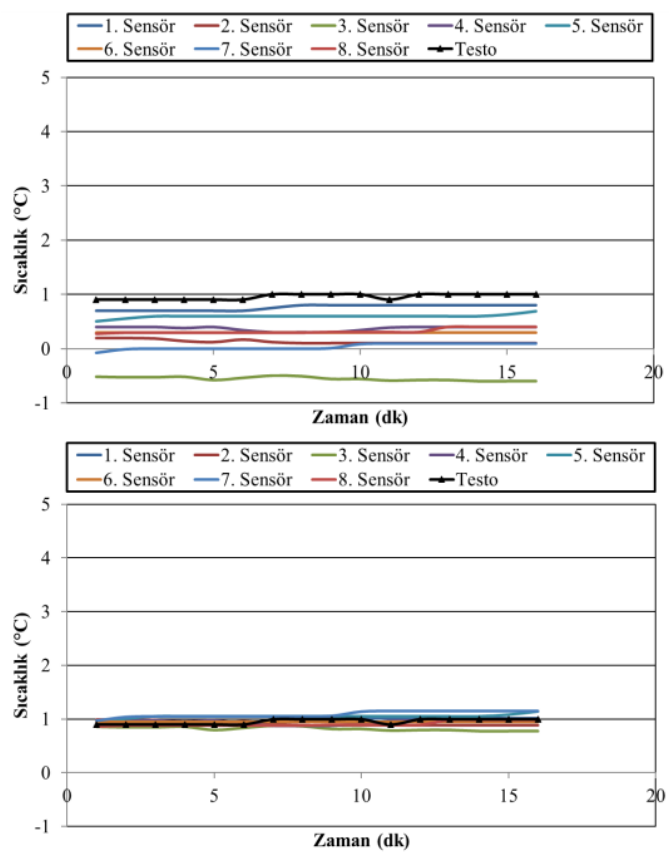

Şekil 9. Düşük sıcaklıktaki $\left(\cong 1^{\circ} \mathrm{C}\right)$ testler için kalibrasyon öncesi (a) ve sonrası (b) sıcaklık değişimleri

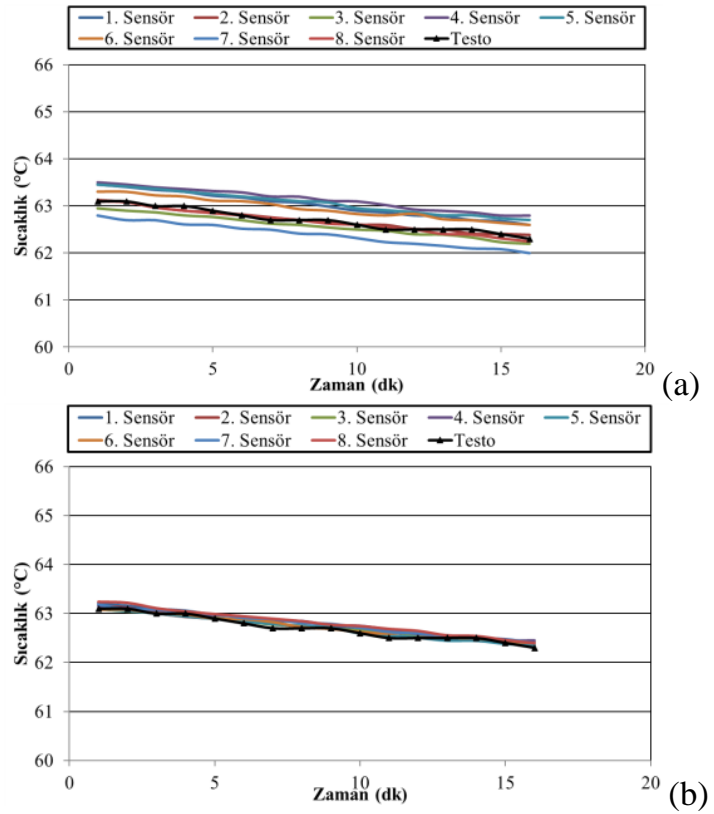

Şekil 10. Yüksek sicaklıktaki $\left(\cong 63^{\circ} \mathrm{C}\right)$ testler için kalibrasyon öncesi (a) ve sonrası (b) sıcaklık değişimleri
Tasarımı yapılan ölçüm sisteminde silindirin 1sıtılması, silindir içerisinde fişek rezistans kullanılarak sağlanmıştır. Isıtılan silindir etrafındaki incelemelere geçmeden önce kullanılan rezistansın yaydığı ısının silindir yüzeyine üniform yayılıp yayılmadığı test edilmiştir. Isıtılan silindir çevresindeki sıcaklık dağılımının yüzeylerde nasıl değiştiğini görmek için farklı 1sitma kapasiteleri (varyak \%30 ve \%100) için farklı perspektiflerde termal kamera ile ölçümler yapılmıştır. Termal kamera görüntüleri Şekil 11'de verilmiştir. Şekil incelendiğinde silindir çevresinde homojen bir sıcaklık dağılımı olduğu dolayısıyla rezistansın ısıyı tüm yüzeylere eşit bir şekilde yaydığı görülmektedir. Yapılan testler kapsamında silindir etrafındaki sıcaklık dağılımı (açılara göre değiş̧im), kanal durgun haldeyken ve varyak tam kapasite (\%100) çalışır durumda iken de incelenmiştir. Şekil 12'de durgun su kanalı içerisinde bulunan silindirin, varyak tam kapasitede çalıştığ 1 esnada yapılan testten elde edilen sıcaklık ölçüm sonuçları verilmiştir. Silindir etrafındaki farklı açılara karşılık gelen sıcaklık değişimleri incelendiğinde, silindir yüzeyinde homojen bir sıcaklık dağılımı olduğu görülmektedir.
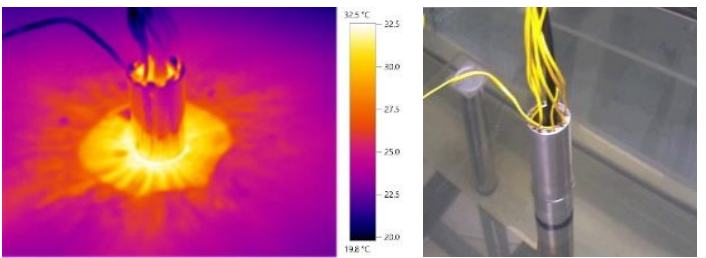

(a)

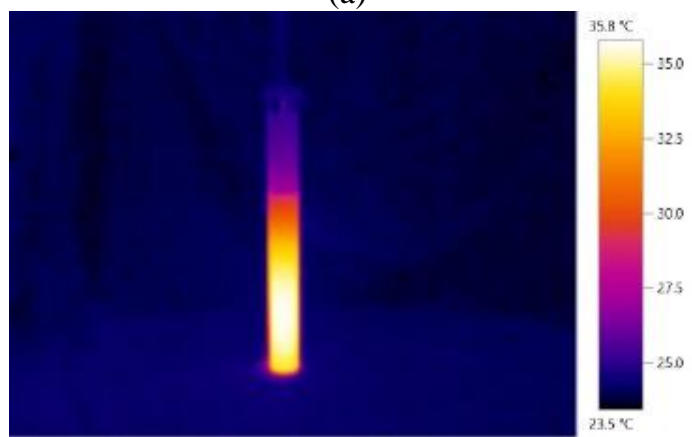

(b)

Şekil 11. Silindir etrafındaki sıcaklık dağılımının durgun kanalda su içerisinde (a) ve diş ortam havasinda (b) görüntülenmesine ait görsel 


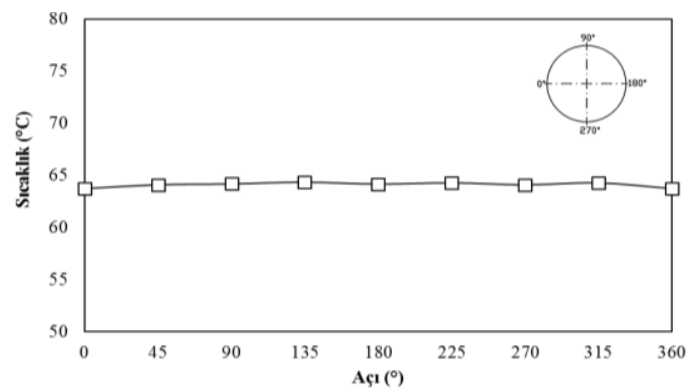

Şekil 12. Durgun kanalda 1sitılan silindirin farklı noktalarındaki (açı) sıcaklık değişimi

Kontrolü ve testleri yapılan sıcaklık ölçüm sisteminin ilk ölçüm sonuçlarının değerlendirilebilmesi amacıyla silindir yüzeyindeki sıcaklık dağılımı farklı Re sayıları için incelenmiş ve her bir Re sayısındaki sıcaklık değişimleri Şekil 13'de verilmiştir. Çalışmada laminar
( $\operatorname{Re} \leq 2300)$, geçiş $(2300 \leq \operatorname{Re} \leq 4000)$ ve türbülanslı $(\mathrm{Re} \geq 5000)$ akış yapılarında silindir etrafındaki sıcaklık değişimi incelenmiştir [12]. Laminar akışta akışkan parçacıkları bir yörünge (akım çizgisi) doğrultusunda düzenli bir şekilde akarken, türbülanslı akış yapısında dönen girdaplardan kaynaklı olarak düzensiz bir akış yapısı oluşmaktadır. Sınır tabakanın Reynolds sayısına göre değişmesi nedeniyle, silindir üzerinden koparak oluşan girdapların yapısı da akışın Reynolds sayısına göre değişiklik göstermektedir. Şekil 13 incelendiğinde, akış hızının yükselmesiyle (Re sayısı arttıkça), akış yapısındaki düzensizliklerden kaynaklı olarak silindir yüzeyindeki sıcaklıkların düştüğü görülmektedir. Şekilden ayrıca, sıcaklık değerlerinin silindir yüzeyindeki akışa bağlı olarak açılara göre de değiştiği görülmektedir.

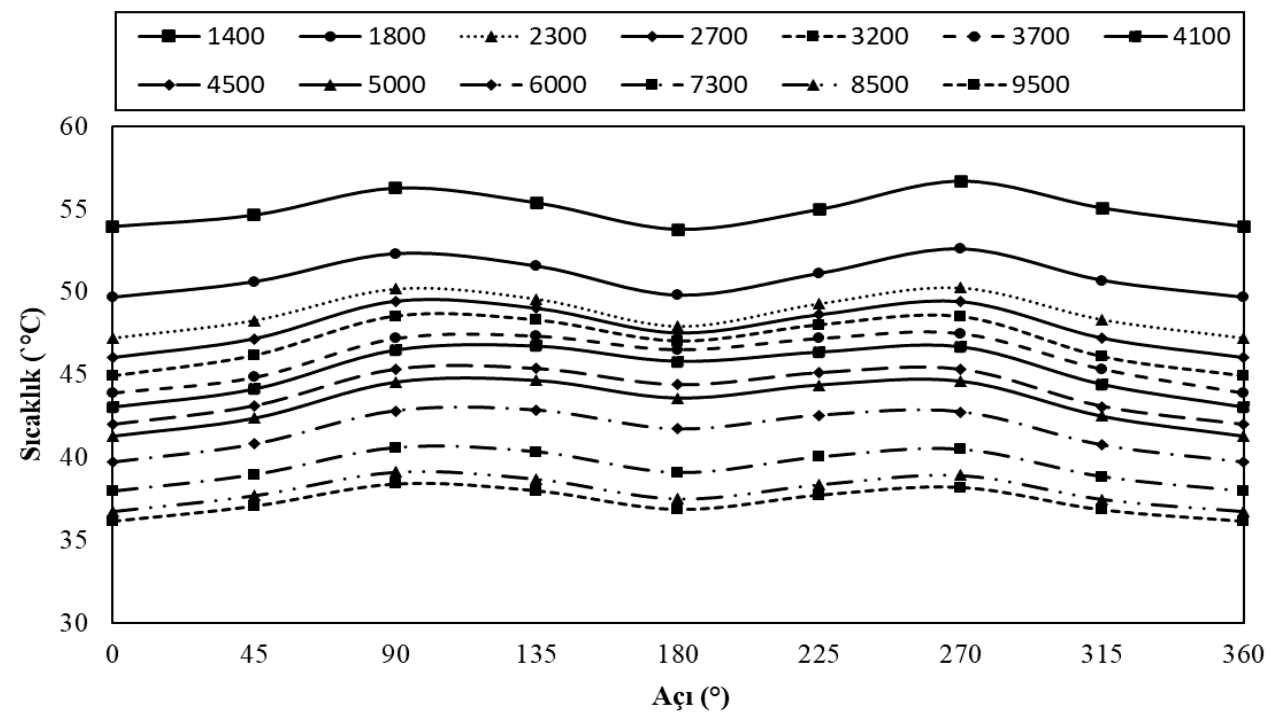

Şekil 13. Farklı Reynolds sayılarında ölçüm noktalarındaki sıcaklık değişimi

\section{SONUÇ}

Literatürde yapılan çalışmalarda cisimler etrafındaki akış yapısı incelenirken termal etkiler için genelde akışkan ortamı olarak hava kullanılmıştır. Sızdırmazlık problemi nedeni ile su içerinde termal ölçümlere az sayıda rastlanılmıştır. Termal etkilerden kaynaklı yoğunluk değişimi ile silindir yüzeyinde oluşabilecek yukarı yönlü hareketleri önleyebilmek için silindir yüzeyi sıcaklığı ve iş akışkanı olan su sıcaklığı arasındaki fark düşük tutulmuştur. Çalışmada, 1sıtılan bir silindir etrafındaki 1sı geçişinin değişimini inceleyebilmek için Osmaniye Korkut Ata Üniversitesi, İleri Akışkanlar Mekaniği Laboratuvarlarında su kanalında kullanılmak üzere bir sıcaklık ölçüm sistemi tasarlanıp, kurulmuş ve sıcaklık ölçümleri başarı ile alınmıştır. 
Gerçekleştirilen ilk deneylerden, sistemin hassas ve düzenli bir şekilde çalıştığı görülmüştür. Deneylerden elde edilen sonuçlar ile tasarım sırasında öngörülen değerler arasında iyi bir uyum olduğu belirlenmiştir.

\section{TEŞEKKÜR}

$\mathrm{Bu}$ çalışma Osmaniye Korkut Ata Üniversitesi Bilimsel Araştırma Projeleri Birimi (OKÜBAP) ve Türkiye Bilimsel ve Teknolojik Araştırma Kurumu (TÜBİTAK) tarafından sirasıyla OKÜBAP-2019PT3-021 ve TÜBİTAK-218M357 projeleri kapsamında desteklenmiştir. OKÜBAP ve TÜBİTAK'a desteklerinden dolayı teşekkür ederiz.

\section{KAYNAKLAR}

1. Cebula, A., Taler, J., Ocłoń, P., 2018. Heat Flux and Temperature Determination in a Cylindrical Element with the Use of Finite Volume Finite Element Method. International Journal of Thermal Sciences, 127, 142-157.

2. Liptak, B.G., 2002. Instrument Engineers Handbook, $3^{\text {rd }}$ ed. CRC Press.

3. Govinder, K., Slabber, J.F., Meyer, J.P., 2020. External Surface Temperature Measurements for the Heat Transfer Analysis of Internally Heated Cylindrical Clad-tubes Subjected to External Forced Convection Bulk Water Coolant Thermal-hydraulic Conditions. Nuclear Engineering and Design, 368, 110779.

4. Li, Y., Zhang, Z., Zhao, C., Hao, X., Dong, N., Yin, W., Pang, Z., 2020. Laser Based Method for Dynamic Calibration of Thermocouples. Applied Thermal Engineering, 174, 115276.

5. Tsutsui, T., Igarashi, T., 2006. Heat Transfer Enhancement of a Circular Cylinder. Journal of Heat Transfer, 128(3), 226-233.

6. Gau, C., Wu, J.M., Liang, C.Y., 1999. Heat Transfer Enhancement and Vortex Flow Structure Over a Heated Cylinder Oscillating in the Crossflow Direction. Journal of Heat Transfer, 121, 789-795.

7. Euler, M., Zhou, R., Hochgreb, S., Dreizler, A., 2014. Temperature Measurements of the Bluff Body Surface of a Swirl Burner Using Phosphor
Thermometry. Combustion and Flame, 161(11), 2842-2848.

8. Yan, W., Panahi, A., Levendis, Y.A., 2020. Spectral Emissivity and Temperature of Heated Surfaces Based on Spectrometry and Digital Thermal Imaging-validation with Thermocouple Temperature Measurements. Experimental Thermal and Fluid Science, 112, 110017.

9. Ghorbani-Tari, Z., Chen, Y., Liu, Y., 2017. Endwall Heat Transfer of a Rectangular Bluff Body at Different Heights: Temperature-sensitive Paint Measurement and Computational Fluid Dynamics. Applied Thermal Engineering, 122, 697-705.

10. Tsutsui, T., Igarashi, T., Nakamura, H., 2001. Drag Reduction and Heat Transfer Enhancement of a Square Prism. JSME International Journal Series B Fluids and Thermal Engineering, 44(4), 575-583.

11. Saydam, D.B., 2020. Aktif Akış Kontrol Tekniği Uygulanan Bir Silindir Etrafında Sicaklık ve Hız Dağılımlarının Deneysel Olarak İncelenmesi, Osmaniye Korkut Ata Üniversitesi, Fen Bilimleri Enstitüsü, Yüksek Lisans Tezi, 185, Osmaniye.

12. Çengel, Y.A., Cimbala, J.M., Engin, T., 2012. Akışkanlar Mekaniği: Temelleri ve Uygulamaları, Güven Kitabevi. 